\title{
The Clinical Characteristics of Lower Lumbar Osteoporotic Compression Fractures Treated by Percutaneous Vertebroplasty: A Comparative Analysis of 120 Cases
}

\author{
Seok Han, Heung-Sik Park, Yong-Hun Pee, Seong-Hoon Oh, II-Tae Jang \\ Department of Neurosurgery, Nanoori Incheon Hospital, Incheon, Korea
}

Objective: The purpose of this study is to provide accurate understanding of clinical presentations and surgical outcomes as well as to identify the unique characteristics of lower lumbar osteoporotic compression fracture (OCF).

Methods: Clinical data were collected from 120 patients who had L3, L4 or L5 percutaneous vertebroplasty (PVP) performed from 2008 to 2012 at the single institute. L4 or L5 PVP patients were classified into group 1 and group 2 was for L3 PVP patients. Medical records were retrospectively investigated at 1 month after PVP. Long term follow-up results were obtained at a median value of 22 months after PVP.

Results: $75 \%$ of the patients in group 1 were not associated with traumatic events, $71 \%$ presenting with leg radiating symptoms and $46 \%$ requiring an additional decompressive surgery, more often than those in group 2 . These differences are statistically significant $(p<0.05)$. The short term medical record review demonstrated that only $73 \%$ of patients in group 1 were ameliorated with regard to back motion pain, whereas those in group 2 reported $87.7 \%$ rates of amelioration in identical category $(p<0.05)$. The long term follow up confirmed a significantly worse outcome in group 1 , with only $55.7 \%$ of patients reporting amelioration in their pain or functional status, but $71.7 \%$ rate of amelioration in group 2 .

Conclusion: The OCFs at the L4 or L5 level have different clinical characteristics from those at upper levels of the lumbar spine.

Key Words: Lower lumbar fracture $\cdot$ Percutaneous vertebroplasty $\cdot$ Clinical presentation $\cdot$ Surgical outcome

\section{INTRODUCTION}

There have been numerous studies evaluating the anatomical distribution of vertebral fractures and consistently showing two prevalent peaks of vertebral fractures: the first one in the mid-thoracic spine region (T7/T8) and another one in the thoraco-lumbar junction (TLJ) ${ }^{1,3,8,17,23,27}$. In these previous studies, approximately $4 \%$ of thoraco-lumbar vertebral compression fractures occur at L4 level ${ }^{1,3,8,17,23,27)}$. Furthermore, fractures of the $5^{\text {th }}$ lumbar vertebra are quite uncommon, representing only $1.2 \%$ of overall spine fractures and $2.2 \%$ of

\footnotetext{
- Received: July 5, 2013 • Revised: September 20, 2013

- Accepted: September 23, 2013

Corresponding Author: ll-tae Jang, MD, PhD

Department of Neurosurgery, Nanoori Incheon Hospital, Bupyeong-dong

124-5, Bupyeong-gu, Incheon 403-010, Korea

Tel: +82-32-460-3304, Fax: +82-32-514-0210

E-mail: torcula@naver.com

®This is an Open Access article distributed under the terms of the Creative

Commons Attribution Non-Commercial License (http://creativecommons.org/ licenses/by-nc/3.0/) which permits unrestricted non-commercial use, distribution, and reproduction in any medium, provided the original work is properly cited.
}

thoraco-lumbar fractures ${ }^{9)}$. On the other hand, according to the previous studies on percutaneous vertebroplasty (PVP) or kyphoplasty, the incidence of PVP at L3, L4 and L5 is about 9-13\%, 5-9\% and 2-5\% respectively of all their thoraco-lumbar PVP or kyphoplasty procedures $5,18,21,28,29)$. Therefore, the approximate incidence of PVP at L3 is near to the sum of incidence of PVP at L4 or L5. As a result of performing over 200 PVP cases for compression fracture at a single institute annually, the authors identified distinct characteristics, clinical presentations and surgical outcomes of patients with lower lumbar compression fractures (L4 or L5).

As the pioneers, Deramond and Galibert reported their first seven procedures in $1987^{10)}$, and PVP has been used to manage vertebral compression fractures ${ }^{15}$. There also have been studies on the factor, fracture level in thoraco-lumbar spine, that influences the result of PVP with regard to back motion pain $^{2,11,14,25,28)}$. However, most previous authors did not separate the clinical features and surgical outcomes of patients with $\mathrm{L} 3$ compression fractures from those with L4 or L5 compression fractures ${ }^{2,11,13,14,18,23,24,28)}$. If the clinical feartures and the surgical outcomes of L3 fracture were significantly different from those of L4 or L5 fractures despite classifying L3, 
L4 and L5 as the lower lumbar spine, those of L3 level fracture, almost half proportion of the lower lumbar spine fractures, could make some confusion and ambiguousness in analysing those of L4 and/or L5 level fractures.

The authors retrospectively investigated our patients' data to elucidate whether those patients treated for L4 or L5 compression fractures by PVP were similar, in terms of demography, clinical features and surgical outcomes, to those treated for $\mathrm{L} 3$ fractures. We then reviewed the literatures to compare the surgical outcomes of patients with L4 or L5 compression fractures with those of patients with TLJ level fractures. Therefore, the purpose of this present study is to provide accurate understanding of clinical presentations and surgical outcomes as well as to identify the unique characteristics of lower lumbar osteoporotic compression fracture (OCF), which would enable physicians and patients to make more informed decisions about whether to perform the procedure and to develop more precise expectations of prognosis.

\section{MATERIALS AND METHODS}

Between October 2008 and July 2012, a total of 762 patients with 948 symptomatic OCFs were consecutively treated with PVP at our single institution. PVP was performed between T5 and S1 (Fig. 1). All procedures were performed by the same team, who obtained a detailed and standardized history. Preoperative clinical data were collected retrospectively from the medical records and assembled in database by one of the authors $(\mathrm{SH})$. There were $105 \mathrm{~L} 3$ (11\% of all procedures), 75/L4 (8\%) and 46/L5 (4.8\%) OCF patients respectively. Of these cases, the patients with multiple fractures were excluded for the level homogeneity. Hence, a total of 120 patients (17 male and 103 female) were investigated, in which there were 57 patients with L3, 40 patients with L4 and 23 patients with L5 OCFs respectively and they were all treated by PVP (no kyphoplasty). All patients demonstrated

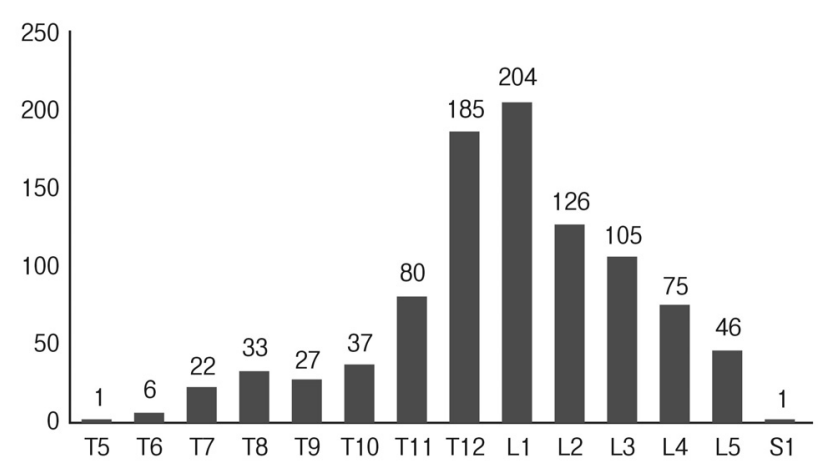

Fig. 1. Histogram demonstrating the distribution of affected vertebral levels treated by percutaneous vertebroplasty. acute agonizing or chronic severe focal back motion pain, who did not respond to bed rest or analgesics at least for 2 weeks. Preoperative data included the presence or absence of previous history of PVP or lumbar decompressive surgery, recent trauma history prior to occurrence of acute compression fracture, leg radiating symptoms and value of bone mineral density (BMD). Not every medical record included documentation of $\mathrm{BMD}$ value. Postoperative data included some information about the presence or absence of cement leakage, subsequent fracture and additional lumbar decompressive surgery. On postPVP plain images and magnetic resonance imaging (MRI), a single observer determined whether there was cement leakage or not. We also measured preoperative and postoperative (6 mo. after PVP) vertebral body compression ratio by calculating the height of anterior-posterior (AP) vertebral wall ratio on the lateral radiography ${ }^{19)}$. Therefore, a smaller AP ratio implies a greater degree of compression or wedge deformity. Initially, the data from L5 OCF patients were compared with those from L4 OCF patients by use of chi-square statistics and Students t-test $(\mathrm{p}<0.05)$. Thereafter, the patients with L4 or L5 OCFs were grouped (group 1) and they were compared with those with L3 OCFs (group 2) for the insignificant variables from initial comparisons. The out-patients follow-up interview and examination were performed at 1 month after PVP. The postoperative back motion pains and leg symptoms were graded by the operating surgeons as improved, unchanged or worse. In addition, long-term follow-up data were obtained via telephone interview in 105 (87.5\%) of 120 patients at a median value of 22 months (range, 2-47 mo.) after PVP. Telephone interviews were performed by a third party, who was blinded and not involved in the treatment. The patients' preoperative economic and functional statuses were compared with their current statuses using Prolo economic and functional grading scale ${ }^{22}$ (Table 1). Patients were determined to have an improved score if either their economic or functional status, such as house-working or daily living activities improved after PVP or to have a worse score if either status was worse after PVP. Furthermore, an additional longterm outcome of leg pain was graded by patients as improved, unchanged or worse.

\section{RESULTS}

There was no statistically significant difference in incidence of multiple fractures between L3, L4 and L5, which were $46 \%$, $47 \%$, and $50 \%$ respectively ( $\mathrm{p}>0.05$ ).

The characteristics of 63 patients with single level L4 or L5 OCF are listed in Table 2. In the previous PVP histories, there was statistically significant difference between L4 and 
Table 1. Prolo economic and functional rating score ${ }^{22)}$

\begin{tabular}{|c|c|}
\hline Score & Description \\
\hline \multicolumn{2}{|c|}{ Economic status } \\
\hline El & Complete invalid \\
\hline E2 & $\begin{array}{l}\text { No gainful occupation (including ability to do } \\
\text { housework or continue retirement activities) }\end{array}$ \\
\hline E3 & Able to work but not at previous occupation \\
\hline E4 & $\begin{array}{l}\text { Working at previous occupation on part-time } \\
\text { or limited basis }\end{array}$ \\
\hline E5 & $\begin{array}{l}\text { Working at previous occupation with no restriction } \\
\text { of any kind }\end{array}$ \\
\hline \multicolumn{2}{|c|}{ Functional status } \\
\hline $\mathrm{Fl}$ & Total incapacity (or worse than preoperative) \\
\hline $\mathrm{F} 2$ & $\begin{array}{l}\text { Mild to moderate level of low back pain and/or } \\
\text { sciatica (or pain same as preoperative but able to } \\
\text { perform all daily tasks of living) }\end{array}$ \\
\hline F3 & $\begin{array}{l}\text { Low level of pain and able to perform all activities } \\
\text { except sports }\end{array}$ \\
\hline $\mathrm{F} 4$ & $\begin{array}{l}\text { No pain, but has had one or more recurrences } \\
\text { of low back pain or sciatica }\end{array}$ \\
\hline F5 & $\begin{array}{l}\text { Complete recovery, no recurrent low back pain, } \\
\text { and able to perform all previous sports activities }\end{array}$ \\
\hline
\end{tabular}

Table 2. Summary of patient characteristics $(L 4, L 5)$

\begin{tabular}{lccc}
\hline \hline & \multicolumn{2}{c}{ Level of fracture } & \\
\cline { 2 - 3 } & 44 & L5 & \\
\hline No. of fractures & 40 & 23 & \\
Age (yr) & $73.9 \pm 8.5$ & $70.4 \pm 7.6$ & $\mathrm{NS}^{*}$ \\
No. male & $5 / 40(13 \%)$ & $3 / 23(13 \%)$ & $\mathrm{NS}$ \\
Previous PVP & $5 / 40(13 \%)$ & $8 / 23(35 \%)$ & $<0.05$ \\
Compression ratio & $91.8 \pm 12.7 \%$ & $101 \pm 15.8 \%$ & $\mathrm{NS}$ \\
(pre OP) & & & \\
Previous lumbar & $6 / 40(15 \%)$ & $3 / 23(13 \%)$ & $\mathrm{NS}$ \\
surgery & & & \\
Trauma history & $10 / 40(25 \%)$ & $6 / 23(26 \%)$ & $\mathrm{NS}$ \\
Leg radiating & $29 / 40(73 \%)$ & $16 / 23(70 \%)$ & $\mathrm{NS}$ \\
symptom & & & \\
BMD (mg Ca-HA/ml) & $46.4 \pm 22.6$ & $45.0 \pm 21.3$ & $\mathrm{NS}$ \\
Compression ratio & $93.6 \pm 13.5 \%$ & $100 \pm 15.0 \%$ & $\mathrm{NS}$ \\
(6 month) & & & \\
Cement leakage & $17 / 40(43 \%)$ & $9 / 23(39 \%)$ & $\mathrm{NS}$ \\
Subsequent fracture & $8 / 40(20 \%)$ & $6 / 23(26 \%)$ & $\mathrm{NS}$ \\
Further lumbar & $18 / 40(45 \%)$ & $11 / 23(48 \%)$ & $\mathrm{NS}$ \\
surgery & & &
\end{tabular}

NS: not significant, BMD: bone mineral density, OP: operation.

*Students t-test.

L5 $(\mathrm{p}<0.05)$ as well as L3 and L5 OCFs $(\mathrm{p}<0.05)$. In analysis of the medical chart review and follow up interview on the telephone, there was no statistical difference in postoperative back motion pain, leg radiating pain and functional or economic status between L4 and L5 OCF patients ( $\mathrm{p}>0.05$ ). 56\% $(13 / 23)$ of L5 OCFs and 30\% (12/40) of L4 had not anterior
Table 3. Summary of patient characteristics (L4+L5, L3)

\begin{tabular}{|c|c|c|c|}
\hline & \multicolumn{2}{|c|}{ Level of fracture } & \multirow[b]{2}{*}{$\mathrm{p}$-value } \\
\hline & $\mathrm{L} 4+\mathrm{L} 5$ & L3 & \\
\hline No. of fractures & 63 & 57 & \\
\hline Age (yr) & $72.6 \pm 8.3$ & $71.7 \pm 9.1$ & $\mathrm{NS}^{*}$ \\
\hline No. male & $8 / 63(13 \%)$ & $9 / 57(16 \%)$ & NS \\
\hline $\begin{array}{l}\text { Compression ratio } \\
\text { (pre OP) }\end{array}$ & $95.2 \pm 14.5 \%$ & $81.7 \pm 16 \%$ & $\mathrm{NS}^{*}$ \\
\hline $\begin{array}{l}\text { Previous lumbar } \\
\text { surgery }\end{array}$ & $9 / 63(14 \%)$ & $9 / 57(16 \%)$ & NS \\
\hline Trauma history & 16/63 (25\%) & $28 / 57(49 \%)$ & $<0.05$ \\
\hline $\begin{array}{l}\text { Leg radiating } \\
\text { symptom }\end{array}$ & 45/63 (71\%) & $24 / 57(42 \%)$ & $<0.05$ \\
\hline $\mathrm{BMD}$ (mg Ca-HA/ml) & $45.9 \pm 21.9$ & $46.3 \pm 18.0$ & $\mathrm{NS}^{*}$ \\
\hline $\begin{array}{l}\text { Compression ratio } \\
\text { (6 month) }\end{array}$ & $96.2 \pm 14.3 \%$ & $81 \pm 16.6 \%$ & $N S^{*}$ \\
\hline Cement leakage & 26/63 (41\%) & 16/57(28\%) & NS \\
\hline Subsequent fracture & 14/63 (22\%) & 6/57(11\%) & NS \\
\hline $\begin{array}{l}\text { Further lumbar } \\
\text { surgery }\end{array}$ & 29/63 (46\%) & 9/57(16\%) & $<0.05$ \\
\hline
\end{tabular}

wedge deformity but biconcave or uni-concave deformity at middle vertebral body portion.

The characteristics of group 1 were compared with those of group 2 except the sole significant variable (previous PVP) from initial comparison at Table 3. The causes of leg radiating pain were mostly combined with intra-canalicular stenosis, disc herniation or partly the encroachment of corresponding intervertebral foramen by height loss due to compression fractures. Not all the cases with leg radiating pain required further lumbar decompressive surgery. In group 1, 64\% (29/45) of cases with leg radiating symptoms needed further decompressive lumbar surgery, whereas 38\% (9/24) of cases did in group 2. There were 5 patients who required the foraminal decompression surgery by paraspinal approach or fusion surgery during or after PVP in group 1 (2 patients with L4 OCF and 3 patients with L5 OCF), in which functional or economic status of 4 patients (80\%) was improved and 3 patients (60\%) showed leg radiating pain improvements on the long-term follow up interviews. However, all further lumbar surgeries were performed for the combined intracalicular pathologies, such as lumbar disc herniation or lateral recess stenosis in group 2. There were trends toward the higher frequency of cement leakage and needs for further PVP due to subsequent fractures in group 1 compared with those in the group 2 (41\% versus $28 \%$, $22 \%$ versus $11 \%$ respectively), however these did not reach statistical significance ( $p>0.05$ ). Fig. 2 showed clinical success rates using Prolo scale and there was statistically significantly worse long-term outcome in group $1(\mathrm{p}<0.05)$. Only $56 \%$ pa- 


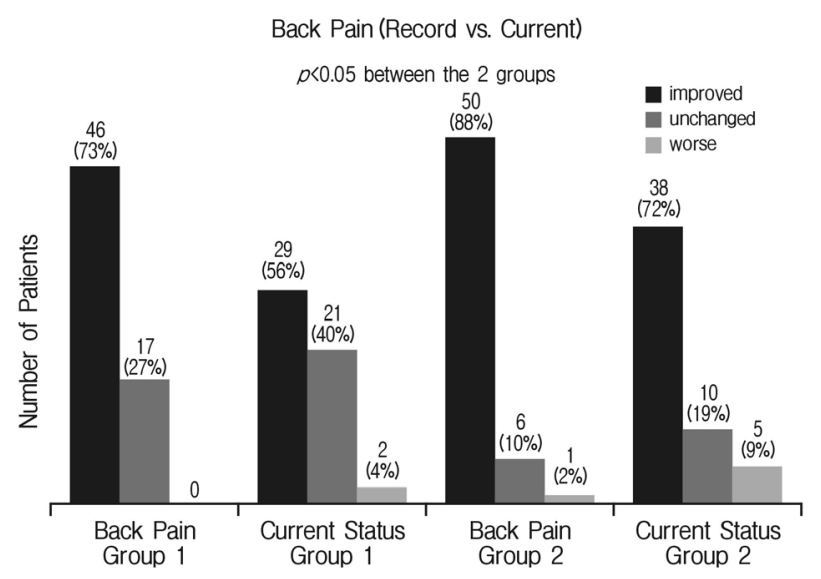

Fig. 2. Comparison of the short term results of back pain based on medical records and long term results from current status through telephone interview

tients showed improvement in economic or functional statuses in group 1 , but $72 \%$ in group 2 . There was no change of statuses in $40 \%$ of group 1 patients after PVP, on the contrary to those in $19 \%$ of group 2 . The additional long-term follow up results for leg pain were illustrated in Fig. 3. Meanwhile, the long-term follow up results of patients with leg radiating symptom in group 1 showed leg pain improvements after further decompressive lumbar surgery in 50\% (13/26) patients, whereas $27 \%(3 / 11)$ patients were improved without additional decompressive surgery. In group 2, 56\% (5/9) patients with leg pain were improved after further decompressive lumbar surgery, on the other hand, 38\% (5/13) patients showed improvement without additional decompressive lumbar surgery. However, there were no statistically significant differences between the two groups ( $p>0.05)$.

\section{DISCUSSION}

Osteoporotic vertebral compression fractures are not uncommon disease in the elderly people and can manifest as severe pain, functional deterioration and limited mobility. Conventional treatments, such as bed rest, bracing, and physical therapy, can result in frequent adverse effects. Furthermore, osteoporotic vertebral compression fractures can cause serious complications during surgery as well as after surgery, such as vertebral reconstruction or fusion operation under general anesthesia. Therefore, PVP is considered the treatments of choice to relieve pain and to stabilize vertebrae. Although it has been reported that PVP has a lot of advantage, the patient population that is most likely to benefit from this procedure is still uncertain ${ }^{1,13,20)}$, and there have also been investigations on unfavorable outcomes and the levels of vertebral

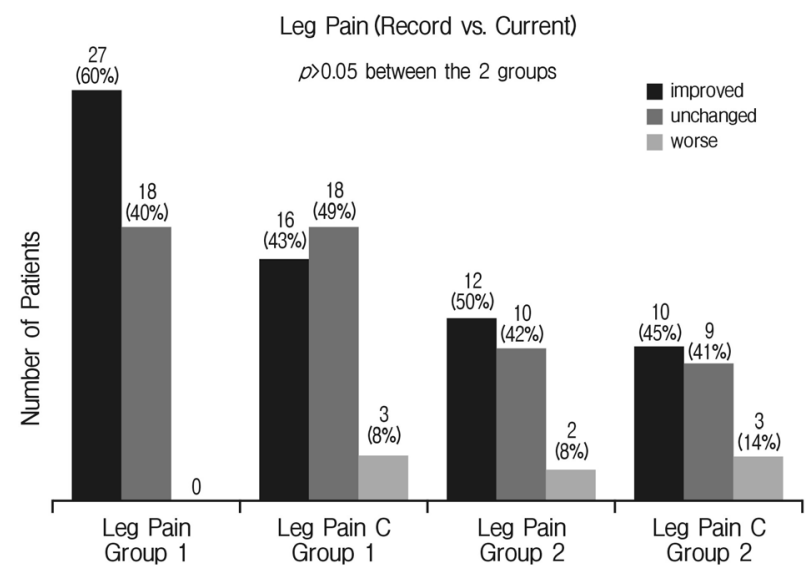

Fig. 3. Comparison of the short term results of leg pain based on medical records and long term results through telephone interview.

fractures as influencing factors ${ }^{2,11,14,25,28)}$. However, most of these studies included L3 level as lower lumbar spine ${ }^{2,11,14,28)}$. Ryu and Park ${ }^{25)}$ divided the fracture levels into four groups (upper and lower parts in thoracic and lumbar vertebrae respectively), and categorized L4 or L5 into lower lumbar vertebrae. However, their sample size was 215 patients with 383 symptomatic OCF. Furthermore, their cases with lower lumbar fractures might involve many of cases with multiple fractures. Most of accompanying fractures would be at TLJ, and the excellent effects of PVP at TLJ were well known and self-evident $^{2,5,19,25,28,29,31)}$. Therefore, the inclusion of cases with multiple fractures can confuse the authentic outcomes of PVP for lower lumbar levels in spite of multivariate polytomous logistic regression analysis. Recently, the most notable determining factor during PVP is the concept of cemented vertebral body fraction $(\mathrm{CVBF})^{13,20)}$. To be achievable volume of intravertebral cement is becoming progressively larger as increasing the volume of vertebral body in lower lumbar spine ${ }^{20)}$. Hence, the possibility to obtain an unfavorable outcome would also increase if an amount of cement was not decided in terms of the volume of fractured vertebra body and treated level. However, the ideal needle placement of our procedure was at the anterior third of the vertebral body, and the end point of cement injection during PVP was when the cement reached the posterior quarter of the vertebral body or when significant leakage occurred as described by Jensen et al. ${ }^{12)}$. Therefore, CVBF alone cannot explain our poor result of PVP for L4 or L5 compression fractures.

The lower lumbar OCFs are unique in a number of ways: they are distinctly uncommon compared with fractures at TLJ levels and their symptomatology frequently occurs without any traumatic events, which is combined with leg radiating pain, and outcome after PVP is less satisfactory than that of 
TLJ fracture cases. There have been few studies in which the features of lower lumbar spine fractures have been divided into 2 parts, (1) L3 fracture and (2) L4 or L5 fractures, and the characteristics of their clinical presentations and surgical outcomes have been compared each other.

Our data indicate that L4 and L5 vertebral OCFs are different from those at the L3 level, and fractures at the L3 level are more similar to those occurring at TLJ. Therefore, the results of previously published reports on lower lumbar OCFs including a preponderance of L3 cases may mask the true features of L4 or L5 vertebral fractures. The origin of these differences is unclear, but those patients with L4 or L5 fractures may have their own spinal biomechanics which are different from those with TLJ fractures. In orther words, L4-5 and L5-S1 segments have been reported to bear the highest loads and to undergo the most motion in the sagittal plane ${ }^{30)}$, which means that it is resonable to seperate L3 from lower lumbar spine levels in this study. It is also supported by our findings that even though there were no statistical differences in demographic data and BMD between group 1 and group 2 , the group 1 had the significantly higher incidence of nontraumatic fractures than that of group 2. This different biomechanics may prevent these patients from achieving the typical excellent outcome with regard to back motion pain experienced in PVP for TLJ fractures. Further clue to this unfavorable result of PVP for L4 or L5 compression fracture can be found in the previous literatures in which Almehed et al. ${ }^{1)}$ and $\mathrm{El}$ Maghraoui et al. ${ }^{8)}$ demonstrated and illustrated that compression severity was highest in the lower lumbar spine. Also, Alvarez et al. ${ }^{2)}$ insisted that favorable result of PVP could be expected in patients with the vertebral height loss less than 70\%. Their study revealed that PVP for patients with more than $70 \%$ vertebral height loss was technically difficult to place the needle safely into the vertebral body with a high incidence of cement leakage into disc space, and the complete relief was limited to less than $30 \%$ of patients ${ }^{2)}$. At last, our data demonstrated that group 1 had the higher incidence of cement leakage and rate of subsequent fracture than group 2, which did not reach statistical significance. However this relatively higher rate of subsequent fracture at L4 or L5 level also may contribute to the unfavorable long-term outcome of PVP, which is also suggested by our data that the long-term outcome via telephone interview of group 1 patients could be obtained in 11 patients of 14 patients who experienced the subsequent fracture, in which only 3 patients (27\%) had improvement of their functional or economic status.

The pain relief mechanism of PVP is not clearly elucidated. Thermal $^{7}$, and chemical ${ }^{26}$ mechanisms have been proposed, however increasing strength and stiffness may be the key elements of its principle mechanism considering previous re- ports ${ }^{4,16}$. Chung et al. ${ }^{6}$ used PVP for the treatment of severe leg radiating pain caused by lower lumbar OCF. They showed the excellent results in which all seven patients had experienced dramatic relief of leg radiating pain after cement injection into lower lumbar fractured body through the pedicle on the symptomatic side. Therefore, they concluded that PVP may be an effective modality of ameliorating leg radiating pain caused by OCF combined with foraminal stenosis through local stiffness mechanism. However, they did not show the overall incidence or outcome of this unique symptom by lower lumbar OCF. Furthermore, the outcome of PVP for leg radiating pain was disappointing level (27-56\% of amelioration rate) irrespective of further decompressive lumbar surgery in our data. They suggested the clinical characteristics of those patients and described that objective evidence of radiculopathy was identified upon electromyography (EMG) or neurological examination. However, the radiculopathy caused by foraminal pathology is not confirmed by clinical symptom, EMG and neurological examination, but suspicious. Thus, the definite, widely acceptable and uniform criteria are necessary to confirm this unique symptom of lower lumbar OCF.

The limitations of this study were that there was no detailed investigation on functional outcomes such as short form-36 or Oswestry Disability Index, which should be necessary for making this study more valuable. However, the retrospective nature of this study was limited thorough investigation on their functional outcomes. Thus, we only investigated short term and long term postoperative Prolo scale as clinical outcome. It is not possible to fully devaluate the usefulness of PVP for L4 and L5 OCF according to the long-term follow up results of this study reporting over 50\% improvement, which is not quite good results to compare with those of previous studies ${ }^{2,5,19,25,28,29,31)}$. Therefore, the prospective randomized controlled clinical studies are needed to demonstrate whether PVP is effective at L4 or L5 level OCF and whether those level OCF may be a marker for progressive back pain, radiating pain and overall worse outcomes.

\section{CONCLUSION}

The patients with L5 OCF patients treated by PVP were more likely to have had previous PVP, and the patients with L4 or L5 OCF were more likely to be non-traumatic, presenting leg radiating symptoms and requiring an additional decompressive surgery more often than L3 OCF group. The PVP outcome in terms of postoperative back motion pain is worse for compression fractures at L4 or L5 compared with those treated at $\mathrm{L} 3$ level. 


\section{REFERENCES}

1. Almehed K, Hetenyi S, Ohlsson, C, Carlsten H, Forsblad-d'Elia $\mathrm{H}$ : Prevalence and risk factors of vertebral compression fractures in female SLE patients. Arthritis Res Ther 12:R153, 2010

2. Alvarez L, Perez-Higueras A, Granizo JJ, de Miguel I, Quinones D, Rossi RE: Predictors of outcomes of percutaneous vertebroplasty for osteoporotic vertebral fractures. Spine (Phila Pa 1976) 30:87-92, 2005

3. Angeli A, Guglielmi G, Dovio A, Capelli G, de Feo D, Giannini $S$, et al: High prevalence of asymptomatic vertebral fractures in post-menopausal women receiving chronic glucocorticoid therapy: a cross-sectional outpatient study. Bone 39:253-259, 2006

4. Belkoff SM, Mathis JM, Jasper LE, Deramond H: The biomechanics of vertebroplasty. The effect of cement volume on mechanical behavior. Spine (Phila Pa 1976) 26:1537-1541, 2001

5. Bergmann M, Oberkircher L, Bliemel C, Frangen TM, Ruchholtz S, Kruger A: Early clinical outcome and complications related to balloon kyphoplasty. Orthop Rev (Pavia) 4:e25, 2012

6. Chung SK, Lee SH, Kim DY, Lee HY: Treatment of lower lumbar radiculopathy caused by osteoporotic compression fracture: the role of vertebroplasty. J Spinal Disord Tech 15:461-468, 2002

7. Deramond H, Wright NT, Belkoff SM: Temperature elevation caused by bone cement polymerization during vertebroplasty. Bone 25:17S-21S, 1999

8. El Maghraoui A, Rezqi A, Mounach A, Achemlal L, Bezza A, Ghozlani I: Prevalence and risk factors of vertebral fractures in women with rheumatoid arthritis using vertebral fracture assessment. Rheumatology (Oxford) 49:1303-1310, 2010

9. Finn CA, Stauffer ES: Burst fracture of the fifth lumbar vertebra. J Bone Joint Surg Am 74:398-403, 1992

10. Galibert P, Deramond H, Rosat P, Le Gars D: [Preliminary note on the treatment of vertebral angioma by percutaneous acrylic vertebroplasty]. Neurochirurgie 33:166-168, 1987

11. Hirakawa M, Kobayashi N, Ishiyama M, Fuwa S, Saida Y, Honda $\mathrm{H}$, et al: Radiological findings as favorable predictors of pain relief in patients with osteoporotic compression fractures after percutaneous vertebroplasty: a retrospective study of 156 cases. Jpn J Radiol 30:407-414, 2012

12. Jensen ME, Evans AJ, Mathis JM, Kallmes DF, Cloft HJ, Dion JE: Percutaneous polymethylmethacrylate vertebroplasty in the treatment of osteoporotic vertebral body compression fractures: technical aspects. AJNR Am J Neuroradiol 18:1897-1904, 1997

13. Jin YJ, Yoon SH, Park KW, Chung SK, Kim KJ, Yeom JS, et al: The volumetric analysis of cement in vertebroplasty: relationship with clinical outcome and complications. Spine (Phila Pa 1976) 36:E761-772, 2011

14. Kim YJ, Lee JW, Kim KJ, Chung SK, Kim HJ, Park JM, et al: Percutaneous vertebroplasty for intravertebral cleft: analysis of therapeutic effects and outcome predictors. Skeletal Radiol 39: 757-766, 2010

15. Lapras C, Mottolese C, Deruty R, Lapras C, Jr Remond J, Duquesnel J: [Percutaneous injection of methyl-metacrylate in osteoporosis and severe vertebral osteolysis (Galibert's technic)]. Ann Chir 43:371-6, 1989

16. Liebschner MA, Rosenberg WS, Keaveny TM: Effects of bone cement volume and distribution on vertebral stiffness after verte- broplasty. Spine (Phila Pa 1976) 26:1547-1554, 2001

17. Lunt M, O'Neill TW, Felsenberg D, Reeve J, Kanis JA, Cooper $\mathrm{C}$, et al: Characteristics of a prevalent vertebral deformity predict subsequent vertebral fracture: results from the European Prospective Osteoporosis Study (EPOS). Bone 33:505-513, 2003

18. Majd ME, Farley S, Holt RT: Preliminary outcomes and efficacy of the first 360 consecutive kyphoplasties for the treatment of painful osteoporotic vertebral compression fractures. Spine J 5:244-255, 2005

19. Nam HGW, Jeong JH, Shin IY, Moon SM, Hwang HS: Clinical effects and radiological results of vertebroplasty: over a 2-year follow-up period. Korean J Spine 9(4):334-339, 2012

20. Nieuwenhuijse MJ, Bollen L, van Erkel AR, Dijkstra PD: Optimal intravertebral cement volume in percutaneous vertebroplasty for painful osteoporotic vertebral compression fractures. Spine (Phila Pa 1976) 37:1747-1755, 2012

21. Nieuwenhuijse MJ, van Rijswijk CS, van Erkel AR, Dijkstra SP: The intravertebral cleft in painful long-standing osteoporotic vertebral compression fractures treated with percutaneous vertebroplasty: diagnostic assessment and clinical significance. Spine (Phila Pa 1976) 37:974-981, 2012

22. Prolo DJ, Oklund SA, Butcher M: Toward uniformity in evaluating results of lumbar spine operations. A paradigm applied to posterior lumbar interbody fusions. Spine (Phila Pa 1976) 11: 601-606, 1986

23. Reinhold M, Knop C, Beisse R, Audige L, Kandziora F, Pizanis A, et al: Operative treatment of 733 patients with acute thoracolumbar spinal injuries: comprehensive results from the second, prospective, Internet-based multicenter study of the Spine Study Group of the German Association of Trauma Surgery. Eur Spine J 19:1657-1676, 2010

24. Rho YJ, Choe WJ, Chun YI: Risk factors predicting the new symptomatic vertebral compression fractures after percutaneous vertebroplasty or kyphoplasty. Eur Spine J 21:905-911, 2012

25. Ryu KS, Park CK: The prognostic factors influencing on the therapeutic effect of percutaneous vertebroplasty in treating osteoporotic vertebral compression fractures. J Korean Neurosurg Soc 45:16-23, 2009

26. Seppalainen AM, Rajaniemi R: Local neurotoxicity of methyl methacrylate among dental technicians. Am J Ind Med 5:471477, 1984

27. Siminoski K, Lee KC, Jen H, Warshawski R, Matzinger MA, Shenouda N, et al: Anatomical distribution of vertebral fractures: comparison of pediatric and adult spines. Osteoporos Int 23: 1999-2008, 2012

28. Singh AK, Pilgram TK, Gilula LA: Osteoporotic compression fractures: outcomes after single- versus multiple-level percutaneous vertebroplasty. Radiology 238:211-220, 2006

29. Tanigawa N, Kariya S, Komemushi A, Nakatani M, Yagi R, Kohzai M, et al: Percutaneous vertebroplasty for osteoporotic compression fractures: long-term evaluation of the technical and clinical outcomes. AJR Am J Roentgenol 196:1415-1418, 2011

30. White AA, Panjabi MM: Clinical biomechanics of the spine, Ed2. Philadelphia: JB Lippincott, 1990

31. Winking M, Stahl JP, Oertel M, Schnettler R, Boker DK: Treatment of pain from osteoporotic vertebral collapse by percutaneous PMMA vertebroplasty. Acta Neurochir (Wien) 146:469476, 2004 